\title{
Mathematical processing of results experimental studies of low-temperature modes of drying of capillary-porous materials of spherical shape
}

\author{
Yu.F. Snezhkin, V.M. Paziuk, Zh.O. Petrova \\ Institute of Engineering Thermophysics of NAS of Ukraine, str. Bulakhovskogo, 2, Bldg. 2, \\ Kyiv, 03164, Ukraine \\ Tel.: +380444249638 \\ E-mail:vadim_pazuk@ukr.net
}

Article info: received 15.03.2019, revised 18.03.2019, accepted 27.03.2019

Snezhkin, Yu.F., Pazyuk, V.M., Petrova, Zh.O. (2019) Mathematical processing of results experimental studies of lowtemperature modes of drying of capillary-porous materials of spherical shape, 1(42), doi: 10.26909/csl.1.2019.3

The mathematical processing of experimental data obtained during the drying of spherical form of capillary-porous materials on a convective drying bench allows us to determine the influence of various factors on the process.

The main factors influencing the kinetics of drying of capillary-porous materials of spherical shape are the temperature and velocity of the heat carrier, as well as the initial moisture content of the material. For each factor, the variation levels corresponding to the optimal conditions for conducting experimental studies with low-temperature drying conditions are recommended.

For a mathematical description of the duration of drying of capillary-porous materials, we use an orthogonal composite plan of the second order. As a result, the proposed mathematical model of the process obtained regression equations and the response surface of the duration of drying of capillary-porous materials of spherical shape.

The obtained regression equations of the drying time give a detailed description of the influence of both individual and joint actions of factors, the significance of these parameters is determined by the corresponding coefficients according to Student's criterion.

Also, the adequacy of the mathematical model according to Fisher's criterion, which corresponds to the real object, is checked.

The construction of the response surfaces of the drying time of capillary-porous materials indicates the nature of the effect of these factors in the given range of variation.

Key words: capillary-porous materials, drying, kinetics, regression equation, mathematical model, multivariate experiment, model adequacy.

\section{Математична обробка результатів експериментальних досліджень низькотемпературних режимів сушіння капілярно-пористих матеріалів сферичної форми}

\author{
Ю.Ф. Снєжкін, В.М. Пазюк, Ж.О. Петрова \\ Інститут технічної теплофізики НАН Украӥни, м. Київ, Україна
}

Математична обробка експериментальних даних отриманих при сушінні капілярно-пористих матеріалів сферичної форми на конвективному сушильному стенді дозволяє визначити вплив різних факторів на процес.

Основними факторами, які впливають на кінетику сушіння капілярно-пористих матеріалів сферичної форми є температура та швидкість руху теплоносія, а також початкова вологість матеріалу. Для кожного фактору рекомендовані рівні варіювання, що відповідають оптимальним умовам проведення експериментальних досліджень із низькотемпературними режимами сушіння. 
Для математичного опису тривалості сушіння капілярно-пористих матеріалів застосовуємо ортогональний композиційний план другого порядку. В результаті за запропонованою математичною моделлю процесу отримані регресійні рівняння та поверхні відгуку тривалості сушіння капілярно-пористих матеріалів сферичної форми.

\section{Вступ}

Для більш детального опису кінетики процесу сушіння капілярно-пористих матеріалів сферичної форми необхідно визначити основні параметри, які впливають на процес сушіння.

Створення математичної моделі тривалості сушіння основана на результатах експериментальних досліджень на конвективному сушильному стенді, що дозволяє більш детально оцінити багатофакторний вплив на кінетику сушіння.

Для математичного опису процесу тривалості сушіння капілярно-пористих матеріалів сферичної форми на конвективному сушильному стенді в елементарному шарі проведено ряд експериментальних досліджень [1].

\section{Матеріали та методи дослідження}

Основний вплив на кінетику процесу сушіння капілярно-пористих матеріалів має температура та швидкість сушіння, а також початкова вологість матеріалу. Фактори і рівні варіювання, які впливають на тривалість сушіння капілярно-пористих матеріалів сферичної форми зазначені в таблиці 1.
Згідно плану дослідження проводили з використанням трьох рівнів для кожного фактору - верхнього (+1), нульового (0) і нижнього (-1), кодові значення яких визначали за формулою

$$
\begin{gathered}
x_{1}=\frac{t-t_{0}}{\varepsilon_{1}}=\frac{t-65}{15} ; \quad x_{2}=\frac{V-V_{0}}{\varepsilon_{2}}=\frac{V-1,05}{0,45} ; \\
x_{3}=\frac{W-W_{0}}{\varepsilon_{3}}=\frac{W-17}{5},
\end{gathered}
$$

де $t_{0}, V_{0}, W_{0}$ - значення факторів на основному рівні, відповідно температура та швидкість теплоносія, початкова вологість матеріалу; $\varepsilon_{1}, \varepsilon_{2}, \varepsilon_{3}-$ інтервал варіювання факторів.

Для математичного опису тривалості сушіння капілярно-пористих матеріалів застосовуємо ортогональний композиційний план другого порядку. В ортогональному центральному плануванні критерієм оптимальності плану експерименту є ортогональність стовпців матриці планування. В силу ортогональності планування всі коефіцієнти рівняння регресії визначається незалежно один від одного. Ядро композиційного плану складає план повного факторного експерименту ПФЕ $2^{n}$ [2].

Математичні моделі тривалості сушіння представимо у вигляді рівнянь регресії

$$
\hat{y}=a_{0}+a_{1} x_{1}+a_{2} x_{2}+a_{3} x_{3}+a_{11} x_{1}^{2}+a_{22} x_{2}^{2}+a_{33} x_{3}^{2}+a_{12} x_{1} x_{2}+a_{13} x_{1} x_{3}+a_{23} x_{2} x_{3} .
$$

Таблиця 1.

Фактори і рівні варіювання, які впливають на тривалість сушіння капілярно-пористих матеріалів сферичної форми

\begin{tabular}{|c|c|c|c|}
\hline \multirow{2}{*}{ Показники } & \multicolumn{2}{|c|}{ Фактори } \\
\cline { 2 - 4 } & \multicolumn{2}{|c|}{ Теплоносій } & Матеріал \\
\cline { 2 - 4 } & $\begin{array}{c}\text { Температура } \\
t,{ }^{\circ} C\end{array}$ & $\begin{array}{c}\text { Швидкість } \\
V, \mu / c\end{array}$ & 22 \\
\hline Верхній (+1) & 80 & 1,5 & 17 \\
\hline Середній (0) & 65 & 1,0 & 12 \\
\hline Нижній (-1) & 50 & 0,5 & 5 \\
\hline Інтервал варіювання & 15 & 0,5 & $x_{3}$ \\
\hline Кодове позначення & $x_{1}$ & $x_{2}$ & 22 \\
\hline
\end{tabular}


Коефіцієнти регресії можна визначались за наступними формулами:

$$
\begin{aligned}
& a_{0}=\frac{1}{N} \sum_{k=1}^{N} y_{k}-q \sum_{i=1}^{N} a_{i i} ; \quad a_{i}=b_{1} \sum_{k=1}^{N} x_{i k} y_{k} ; \\
& a_{i j}=b_{2} \sum_{k=1}^{N} x_{i k} x_{j k} y_{k} ; \quad a_{i i}=b_{3} \sum_{k=1}^{N}\left(x_{i k}^{\prime 2}-q\right) y_{k},
\end{aligned}
$$

де $q$ - величина, що забезпечує ортогональність композиційних планів.

$$
q=\frac{1}{N}\left(2^{n}+2 R^{2}\right)=\frac{1}{15}\left(2^{3}+2 \cdot 1,215^{2}\right)=0,73,
$$

$b_{0}, b_{1}, b_{2}, b_{3}$, - елементи дисперсійної матриці плану.

$$
b_{0}=0,0667 ; b_{1}=0,0913 ; b_{2}=0,125 ; b_{3}=0,2298 \text {. }
$$

Рекомендований вигляд матриці планування експерименту і порядок проведення дослідів представлені в таблиці 2.

\section{Результати та їх обговорення}

Результати трьохфакторного експерименту за ортогональним композиційним планом другого порядку, дозволили отримати рівняння квадратичної регресії в кодових змінних для тривалості процесу сушіння в елементарному шарі:

$$
\begin{gathered}
\hat{y}=31,11-11,212 x_{1}-2,087 x_{2}+8,61 x_{3}- \\
-0,328 x_{1}^{2}-0,669 x_{2}^{2}-2,709 x_{3}^{2}+0,5 x_{1} x_{2}-3 x_{1} x_{3} .
\end{gathered}
$$

Дисперсія точки експерименту $S_{k}^{2}$ визначається:

$$
S_{k}^{2}=\frac{1}{m-1} \sum_{l=1}^{m}\left(y_{k l}-\overline{y_{l}}\right)=8 \text {. }
$$

Оцінка дисперсії відтвореності :

$$
S_{y}^{2}=\frac{1}{N} \sum_{j=1}^{N} S_{k}^{2}=\frac{8}{15}=0,53 .
$$

Таблиця 2

Матриця плану і результати експериментів з сушіння капілярно-пористих матеріалів сферичної форми

\begin{tabular}{|c|c|c|c|c|c|c|c|c|c|c|}
\hline \multirow{2}{*}{ № } & \multicolumn{9}{|c|}{ Умови дослідів } & \multirow{2}{*}{$\tau$, хв } \\
\cline { 2 - 12 } & $x_{1}$ & $x_{2}$ & $x_{3}$ & $x_{1}^{2}$ & $x_{2}^{2}$ & $x_{3}^{2}$ & $x_{1} x_{2}$ & $x_{1} x_{3}$ & $x_{2} x_{3}$ & \\
\hline 1. & -1 & -1 & -1 & +1 & +1 & +1 & +1 & +1 & +1 & 30 \\
\hline 2. & +1 & -1 & -1 & +1 & +1 & +1 & -1 & -1 & +1 & 12 \\
\hline 3. & -1 & +1 & -1 & +1 & +1 & +1 & -1 & +1 & -1 & 24 \\
\hline 4. & +1 & +1 & -1 & +1 & +1 & +1 & +1 & -1 & -1 & 9 \\
\hline 5. & -1 & -1 & +1 & +1 & +1 & +1 & +1 & -1 & -1 & 54 \\
\hline 6. & +1 & -1 & +1 & +1 & +1 & +1 & -1 & +1 & -1 & 24 \\
\hline 7. & -1 & +1 & +1 & +1 & +1 & +1 & -1 & -1 & +1 & 48 \\
\hline 8. & +1 & +1 & +1 & +1 & +1 & +1 & +1 & +1 & +1 & 20 \\
\hline 9. & $-1,215$ & 0 & 0 & $+1,472$ & 0 & 0 & 0 & 0 & 0 & 44 \\
\hline 10. & $+1,215$ & 0 & 0 & $+1,472$ & 0 & 0 & 0 & 0 & 0 & 17 \\
\hline 11. & 0 & $-1,215$ & 0 & 0 & $+1,472$ & 0 & 0 & 0 & 0 & 32 \\
\hline 12. & 0 & $+1,215$ & 0 & 0 & $+1,472$ & 0 & 0 & 0 & 0 & 28 \\
\hline 13. & 0 & 0 & $-1,215$ & 0 & 0 & $+1,472$ & 0 & 0 & 0 & 17 \\
\hline 14. & 0 & 0 & $+1,215$ & 0 & 0 & $+1,472$ & 0 & 0 & 0 & 37 \\
\hline 15. & 0 & 0 & 0 & 0 & 0 & 0 & 0 & 0 & 0 & 31 \\
\hline
\end{tabular}


Після проведення дослідів проводимо перевірку відтвореності з використанням критерію Кохрена:

$$
G_{\max }=\frac{S_{k \max }^{2}}{\sum_{k=1}^{N} S_{k}^{2}}=\frac{0,7}{8}=0,0875 .
$$

Для рівня значимості $\alpha=1-\gamma=0,05$ при кількості ступенів вільності $v_{1}=m-1=2, v_{2}=N=15$ за таблицями знаходимо критичне значення статистики критерію: $G_{k p}=0,3346$.

Так як $G_{\max }=0,0875<G_{k p}=0,3346$, то можна зробити висновок про відтвореність експерименту.

Оцінка дисперсії похибки для відповідних коефіцієнтів рівняння регресії визначається:

$$
\begin{gathered}
S_{a 0}^{2}=\frac{b_{0}}{m} S_{y}^{2}+q^{2} \sum_{i=1}^{n} S_{a i i}^{2}=\frac{0,0667}{3} \cdot 0,53+ \\
+0,73^{2} \cdot 0,022 \cdot 3=0,47 ; \quad S_{a 0}=0,68 \\
S_{a i}^{2}=\frac{b_{1}}{m} S_{y}^{2}=\frac{0,0913}{3} \cdot 0,53=0,016 \\
S_{a 1}=S_{a 2}=S_{a 3}=0,13 \\
S_{a i i}^{2}=\frac{b_{3}}{m} S_{y}^{2}=\frac{0,2298}{3} \cdot 0,53=0,041 \\
S_{a 11}=S_{a 22}=S_{a 33}=0,21 \\
S_{a i j}^{2}=\frac{b_{2}}{m} S_{y}^{2}=\frac{0,125}{3} \cdot 0,53=0,022 \\
S_{a 12}=S_{13}=S_{23}=0,15
\end{gathered}
$$

Гіпотеза про статичну значимість оцінок коефіцієнтів рівняння регресії $a_{i}$ перевіряється за допомогою $t$ - критерію Стьюдента

$$
t_{i p}=\frac{\left|a_{i}\right|}{S_{a i}} .
$$

Параметр значно відрізняється від нуля, якщо

$$
t_{i p}>t_{\kappa p}
$$

В протилежному випадку нульова гіпотеза приймається та параметр $a_{i} \in$ статистично не значимим. Критичне значення статистики $t_{k p}$ знаходиться по відповідним таблицям критерію Стьюдента для числа степенем вільності $v=N(m-1)$ та рівня значимості $\alpha=1-\gamma$. Якщо для значення оцінки параметру $\alpha_{i}$ умова $t_{i p}>t_{k p}$ не виконується, то відповідний фактор $є$ не значимим та виключається з рівняння регресії.
Приймаємо рівень значимості $\alpha=1-\gamma=0,05$ i користуючись таблицями критерію Стьюдента для $\alpha=0,05$ і $v=N(m-1)=30$, критичне значення статистики дорівнює $t_{k p}=2,04$.

Значення коефіцієнтів розраховуємо за критерієм Стьюдента за формулою (5) і зводимо в таблицю 3 :

Таблиця 3.

Визначення значимості коефіцієнтів регресії

\begin{tabular}{|c|c|c|}
\hline$\alpha_{i}, \alpha_{i i}, \alpha_{i j}$ & $S_{\alpha i}, S_{\alpha i i}, S_{\alpha i j}$ & $t_{i p}$ \\
\hline$\alpha_{0}=31,11$ & 0,68 & 45,75 \\
\hline$\alpha_{1}=-11,212$ & 0,13 & 86,24 \\
\hline$\alpha_{2}=-2,087$ & 0,13 & 16,05 \\
\hline$\alpha_{3}=8,61$ & 0,13 & 66,23 \\
\hline$\alpha_{11}=-0,328$ & 0,21 & 1,56 \\
\hline$\alpha_{22}=-0,669$ & 0,21 & 3,18 \\
\hline$\alpha_{33}=-2,709$ & 0,21 & 12,9 \\
\hline$\alpha_{12}=0,5$ & 0,15 & 3,33 \\
\hline$\alpha_{13}=-3$ & 0,15 & 20 \\
\hline$\alpha_{23}=0$ & 0 & 0 \\
\hline
\end{tabular}

В отриманому рівнянні (4) оцінки коефіцієнтів $\alpha_{11}=-0,328$ та $\alpha_{23}=0$ виявились не значимими. Коефіцієнти $\alpha_{11}, \alpha_{23}$ виключаємо з рівняння регресії.

Тоді рівняння регресії приймає вигляд:

$$
\begin{aligned}
& \hat{y}=31,11-11,212 x_{1}-2,087 x_{2}+8,61 x_{3}- \\
& -0,669 x_{2}^{2}-2,709 x_{3}^{2}+0,5 x_{1} x_{2}-3 x_{1} x_{3} .
\end{aligned}
$$

Приведене рівняння регресії показує, що всі фактори зазначені в рівнянні регресії є визначальними. Найбільше на тривалість сушіння капілярно-пористих матеріалів впливає температура теплоносія та початкова вологість.

Перевіримо правильність отриманого рівняння регресії. Для цього задамо значення факторів $x_{i}$, які відповідають першому рядку досліду (табл. 2). Тоді:

$$
\begin{gathered}
\hat{y}=31,11-11,212(-1)-2,087(-1)+8,61(-1)- \\
-0,669(+1)-2,709(+1)+0,5(+1)-3(+1)=29,926 .
\end{gathered}
$$


Оцінку дисперсії неадекватності знаходимо за формулою (8)

$$
S_{\text {неад }}^{2}=\frac{1}{N-r} \sum_{j=1}^{N}\left(\overline{y_{j}}-\hat{y}_{j}\right)^{2}=\frac{1}{15-8} \cdot 3,18=0,46 .
$$

Перевірка адекватності математичної моделі результатами експерименту відбувається по $F$ - критерію Фішера за формулою (9)

$$
F_{p}=\frac{S_{\text {неад }}^{2}}{S_{y}^{2}}=\frac{0,46}{0,53}=0,87 .
$$

Для числа степені вільності $v_{2}=N-r=7$ i $v_{1}=N(m-1)=30$ та рівня значимості $\alpha=0,05$ за таблицями знаходимо критичне значення статистики Фішера $F_{k p}=2,35$. Так як $F_{p}=0,87<F_{k p}=2,35$, то математична модель у вигляді рівняння квадратичної регресії адекватна реальному об'єкту.

Перейдемо в рівняння квадратичної регресії від кодованих $x_{i}$ факторів до відповідних фізичних величин

$$
\begin{gathered}
\tau=31,11-11,212 \cdot\left(\frac{t-65}{15}\right)-2,087 \cdot\left(\frac{V-1,05}{0,45}\right)+ \\
+8,61 \cdot\left(\frac{W-17}{5}\right)-0,669 \cdot\left(\frac{V-1,05}{0,45}\right)^{2}-2,709 \cdot\left(\frac{W-17}{5}\right)^{2}+ \\
+0,5 \cdot\left(\frac{t-65}{15}\right) \cdot\left(\frac{V-1,05}{0,45}\right)-3 \cdot\left(\frac{t-65}{15}\right) \cdot\left(\frac{W-17}{5}\right)= \\
=51,096-0,148 \cdot t-9,45 \cdot V+4,32 \cdot W-3,3 \cdot V^{2}- \\
\quad \quad-0,108 \cdot W^{2}-0,074 \cdot t \cdot V-0,04 \cdot t \cdot W .
\end{gathered}
$$

За отриманим рівнянням регресії тривалості сушіння капілярно-пористих матеріалів сферичної форми в елементарному шарі знайдено поверхні відгуку від дії трьох факторів і побудовано в графічній програмі Mathcad.

За поверхнями відгуку, описаними за ортогональним композиційним планом другого порядку, можна знайти проміжні значення тривалості сушіння в залежності від зазначених факторів (рис. 1).

\section{Висновки}

Отримане рівняння регресії та поверхні відгуку тривалості сушіння капілярно-пористих матеріалів сферичної форми від дії трьох факторів показують, що найбільший вплив на тривалість сушіння відбувається від дії температури теплоносія і початкової вологості матеріалу.

Отримані регресійні рівняння тривалості сушіння дають детальну характеристику впливу як окре-
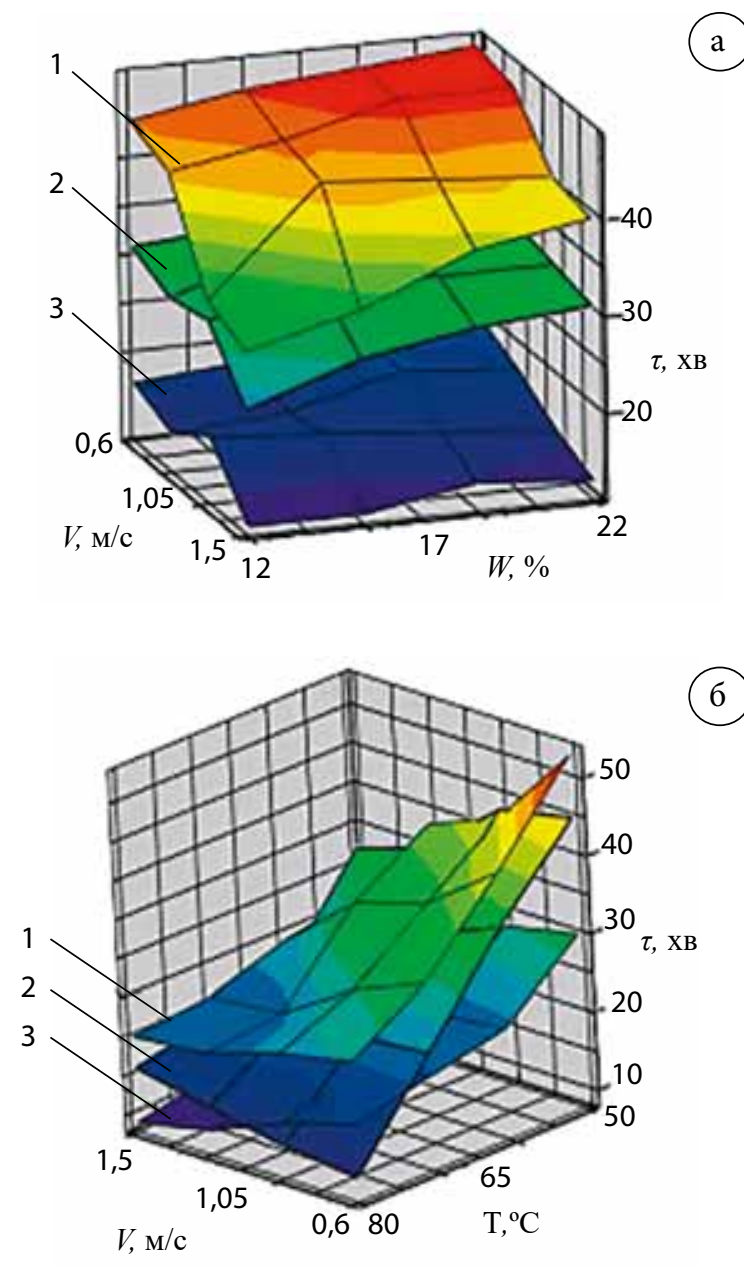

(6)

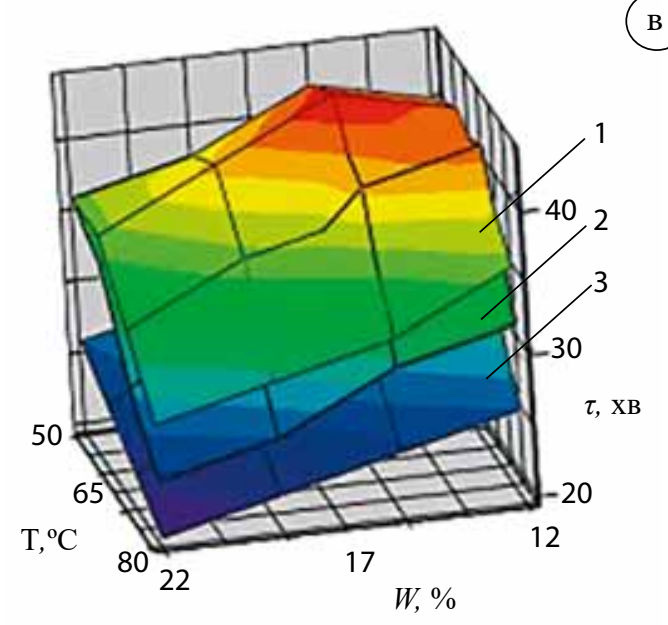

Рис. 1. Поверхні відгуку тривалості сушіння капілярно-пористих матеріалів сферичної форми в елементарному шарі від дії наступних факторів:

а) температури: $1-50{ }^{\circ} \mathrm{C} ; 2-65^{\circ} \mathrm{C} ; 3-80{ }^{\circ} \mathrm{C}$

б) швидкості: $1-0,5 \mathrm{~m} / \mathrm{c} ; 2-1,0 \mathrm{~m} / \mathrm{c} ; 3-1,5 \mathrm{~m} / \mathrm{c}$ в) початкової вологості: 1 - $12 \% ; 2$ - $17 \% ; 3-22 \%$ 
мих так і сумісної дії факторів, значимість цих параметрів визначається відповідними коефіцієнтами за критерієм Стьюдента.

Також перевірена адекватність математичної моделі за критерієм Фішера, що відповідає реальному об'єкту.

Побудова поверхонь відгуку тривалості сушіння капілярно-пористих матеріалів вказує на характер впливу дії зазначених факторів в заданих межах варіювання.

\section{References}

1. Пазюк, В.М. Дослідження низькотемпературних режимів сушіння рослинних капілярно-пористих матеріалів сферичної форми // Кераміка: наука i життя. - 2018. - №4. - С. 7 - 14.

2. Янцевич, А.А., Александров, Ю.А. Планирование эксперимента: Учеб. пособие для студ. экон. и техн. спец. вузов / Народная украинская академия. Х.: Издательство НУА. - 2004. - 208 с. 